\title{
OPTIMIZATION \\ UNDER UNCERTAINTY WITH APPLICATIONS TO PERSONNEL MANAGEMENT PROBLEMS IN TOURISM
}

\begin{abstract}
A large number of problems in production planning and scheduling, location, transportation, finance, and engineering design require that decisions be made in the presence of uncertainty. In the present paper, for improvement or optimization of statistical decisions under parametric uncertainty, a new technique of invariant embedding of sample statistics in a performance index is proposed. This technique represents a simple and computationally attractive statistical method based on the constructive use of the invariance principle in mathematical statistics. Unlike the Bayesian approach, an invariant embedding technique is independent of the choice of priors. It allows one to eliminate unknown parameters from the problem and to find the best invariant decision rule, which has smaller risk than any of the well-known decision rules. In order to illustrate the application of the proposed technique for constructing optimal statistical decisions under parametric uncertainty, we discuss the following personnel management problem in tourism. A certain company provides interpreter-guides for tourists. Some of the interpreter-guides are permanent ones working on a monthly basis at a daily guaranteed salary. The problem is to determine how many permanent interpreter-guides should the company employ so that their overall costs will be minimal? We restrict attention to families of underlying distributions invariant under location and/or scale changes. A numerical example is given.
\end{abstract}

Key words: invariant embedding technique, optimization, personnel management problem

Nicholas A. Nechval, PhD, Professor at University of Latvia, Latvia, e-mail: nechval@junik.lv

** Gundars Berzins, Assistan Professor, University of Latvia, Latvia

*** Vadim Danovich, Associate Professor, University of Latvia, Latvia

K**** Konstantin N. Nechval, Associate Professsor, Transport and Telecommunication Institute, Latvia, e-mail: konstan@tsi.lv 


\section{Introduction}

Most of the operations research and management science literature assumes that the true distributions are specified explicitly. However, in many practical situations, the true distributions are not known, and the only information available may be a time-series (or random sample) of the past data. Analysis of decision-making problems with unknown distribution is not new. Several important papers have appeared in the literature. When the true distribution is unknown, one may either use a parametric approach (where it is assumed that the true distribution belongs to a parametric family of distributions) or a nonparametric approach (where no assumption regarding the parametric form of the unknown distribution is made). Under the parametric approach, one may choose to estimate the unknown parameters or choose a prior distribution for the unknown parameters and apply the Bayesian approach to incorporating the past data available. Parameter estimation is first considered in (Conrad, 1976) and further development is reported in (Liyanage and Shanthikumar, 2005). Scarf (1959) considers a Bayesian framework for the unknown demand distribution. Specifically, assuming that the demand distribution belongs to the family of exponential distributions, the demand process is characterized by the prior distribution on the unknown parameter. Further extension of this approach is presented in (Chu, Shanthikumar and Shen, 2008). Within the nonparametric approach, either the empirical distribution (Liyanage and Shanthikumar, 2005) or the bootstrapping method (e.g. see Bookbinder and Lordahl, 1989) can be applied with the available past data to obtain a statistical decision rule. A third alternative to dealing with the unknown distribution is when the random variable is partially characterized by its moments. When the unknown demand distribution is characterized by the first two moments, Scarf (1958) derives a robust min-max inventory control policy. Further development and review of this model is given in (Gallego and Moon, 1993). In the present paper we consider the case, where it is known that the true distribution function belongs to a parametric family of distributions. It will be noted that, in this case, most stochastic models to solve the problems of control and optimization of system and processes are developed in the extensive literature under the assumptions that the parameter values of the underlying distributions are known with certainty. In actual practice, such is simply not the case. When these models are applied to solve real-world problems, the parameters are estimated and then treated as if they were the true values. The risk associated with using estimates 
rather than the true parameters is called estimation risk and is often ignored. When data are limited and (or) unreliable, estimation risk may be significant, and failure to incorporate it into the model design may lead to serious errors. Its explicit consideration is important since decision rules that are optimal in the absence of uncertainty need not even be approximately optimal in the presence of such uncertainty. The problem of determining an optimal decision rule in the absence of complete information about the underlying distribution, i.e., when we specify only the functional form of the distribution and leave some or all of its parameters unspecified, is seen to be a standard problem of statistical estimation. Unfortunately, the classical theory of statistical estimation has little to offer in general type of situation of loss function. The bulk of the classical theory has been developed about the assumption of a quadratic, or at least symmetric and analytically simple loss structure. In some cases this assumption is made explicit, although in most it is implicit in the search for estimating procedures that have the "nice" statistical properties of unbiasedness and minimum variance. Such procedures are usually satisfactory if the estimators so generated are to be used solely for the purpose of reporting information to another party for an unknown purpose, when the loss structure is not easily discernible, or when the number of observations is large enough to support Normal approximations and asymptotic results. Unfortunately, we seldom are fortunate enough to be in asymptotic situations. Small sample sizes are generally the rule when estimation of system states and the small sample properties of estimators do not appear to have been thoroughly investigated. Therefore, the above procedures of the statistical estimation have long been recognized as deficient, however, when the purpose of estimation is the making of a specific decision (or sequence of decisions) on the basis of a limited amount of information in a situation where the losses are clearly asymmetric - as they are here. In this paper, we propose a new technique to solve optimization problems of statistical decisions under parametric uncertainty. The technique is based on the constructive use of the invariance principle for improvement (or optimization) of statistical decisions. It allows one to yield an operational, optimal information-processing rule and may be employed for finding the effective statistical decisions for many problems of the operations research and management science. The illustrative application of the invariant embedding technique to personnel management problems in tourism is given below 


\section{Invariant Embedding Technique}

This paper is concerned with the implications of group theoretic structure for invariant performance indexes. We present an invariant embedding technique based on the constructive use of the invariance principle for decision-making. This technique allows one to solve many problems of the theory of statistical inferences in a simple way. The aim of the present paper is to show how the invariance principle may be employed in the particular case of improvement or optimization of statistical decisions. The technique used here is a special case of more general considerations applicable whenever the statistical problem is invariant under a group of transformations, which acts transitively on the parameter space (Nechval and Vasermanis, 2004; Nechval, N.A., Berzins, Purgailis, Nechval, K.N. and Zolova, 2008; Nechval, N.A., Nechval, K.N., Danovich and Liepins, 2011; Nechval, N.A., Nechval, K.N. and Purgailis 2011; Nechval, N.A., Nechval, K.N., Purgailis, Rozevskis, 2012; Nechval, N.A., Purgailis, 2012).

\subsection{Preliminaries}

Our underlying structure consists of a class of probability models (X, A, P), a one-one mapping $\psi$ taking $\mathrm{P}$ onto an index set $\Theta$, a measurable space of actions (U, B), and a real-valued function $r$ defined on $\Theta \times \mathrm{U}$. We assume that a group $G$ of one-one $\mathrm{A}$ - measurable transformations acts on $\mathrm{X}$ and that it leaves the class of models (X, A, P ) invariant. We further assume that homomorphic images $\bar{G}$ and $\widetilde{G}$ of $G$ act on $\Theta$ and U, respectively. ( $\bar{G}$ may be induced on $\Theta$ through $\psi ; \widetilde{G}$ may be induced on $\mathrm{U}$ through $r$ ). We shall say that $r$ is invariant if for every $(\boldsymbol{\theta}, \mathbf{u}) \in \Theta \times \mathrm{U}$

$$
r(\bar{g} \boldsymbol{\theta}, \widetilde{g} \mathbf{u})=r(\boldsymbol{\theta}, \mathbf{u}), g \in G .
$$

Given the structure described above there are aesthetic and sometimes admissibility grounds for restricting attention to decision rules $\boldsymbol{\varphi}: \mathrm{X} \rightarrow \mathrm{U}$ which are $(G, G)$ equivariant in the sense that

$$
\boldsymbol{\varphi}(g \mathbf{x})=\widetilde{g} \boldsymbol{\varphi}(\mathbf{x}), \quad \mathbf{x} \in \mathrm{X}, \quad g \in G .
$$

If $\bar{G}$ is trivial and (1), (2) hold, we say $\varphi$ is $G$-invariant, or simply invariant. 


\subsection{Invariant functions}

We begin by noting that $r$ is invariant in the sense of (1) if and only if $r$ is a $G^{\bullet}$-invariant function, where $G^{\bullet}$ is defined on $\Theta \times \mathrm{U}$ as follows: to each $g \in G$, with homomorphic images $\bar{g}, \widetilde{\mathrm{g}}$ in $\bar{G}, \widetilde{G}$ respectively, let $g^{\boldsymbol{\bullet}}(\boldsymbol{\theta}, \mathbf{u})=(\bar{g} \boldsymbol{\theta}, \widetilde{g} \mathbf{u})$, $(\theta, \mathbf{u}) \in(\Theta \times U)$. It is assumed that $\widetilde{G}$ is a homomorphic image of $\bar{G}$.

Definition 1 (Transitivity). A transformation group $\bar{G}$ acting on a set $\Theta$ is called (uniquely) transitive if for every $\boldsymbol{\theta}, \boldsymbol{\vartheta} \in \Theta$ there exists a (unique) $\bar{g} \in \bar{G}$ such that $\bar{g} \boldsymbol{\theta}=\boldsymbol{\vartheta}$. When $\bar{G}$ is transitive on $\Theta$ we may index $\bar{G}$ by $\Theta$ : fix an arbitrary point $\boldsymbol{\theta} \in \Theta$ and define $\bar{g}_{\boldsymbol{\theta}}$, to be the unique $\bar{g} \in \bar{G}$ satisfying $\bar{g} \boldsymbol{\theta}=$ $\boldsymbol{\theta}_{1}$. The identity of $\bar{G}$ clearly corresponds to $\theta$. An immediate consequence is Lemma 1.

Lemma 1 (Transformation). Let $\bar{G}$ be transitive on $\Theta$. Fix $\theta \in \Theta$ and define $\bar{g}_{\boldsymbol{\theta}_{1}}$ as above. Then

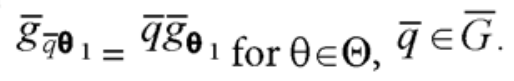

Proof. The identity $\bar{g}_{\bar{a} \boldsymbol{\theta}}, \boldsymbol{\theta}=\bar{q} \boldsymbol{\theta}_{1}=\bar{q} \bar{g}_{\boldsymbol{\theta}}, \boldsymbol{\theta}$ shows that $\bar{g}_{\bar{a} \boldsymbol{\theta}_{\boldsymbol{\theta}}}$ and $\bar{q} \bar{g}_{\boldsymbol{\theta}_{1}}$ both take $\boldsymbol{\theta}$ into $\bar{q} \boldsymbol{\theta}_{1}$, and the lemma follows by unique transitivity.

Theorem 1 (Maximal invariant). Let $\bar{G}$ be transitive on $\Theta$. Fix a reference point $\theta_{0} \in \Theta$ and index $\bar{G}$ by $\Theta$. A maximal invariant $M$ with respect to $G{ }^{\bullet}$ acting on $\Theta \times \mathrm{U}$ is defined by

$$
M(\boldsymbol{\theta}, \mathbf{u})=\widetilde{g}_{\boldsymbol{\theta}}^{-1} \mathbf{u}, \quad(\boldsymbol{\theta}, \mathbf{u}) \in \Theta \times \mathbf{U} .
$$

Proof. For each $(\boldsymbol{\theta}, \mathbf{u}) \in(\Theta \times \mathrm{U})$ and $\bar{g} \in \bar{G}$

$$
M(\bar{g} \boldsymbol{\theta}, \widetilde{g} \mathbf{u})=\left(\widetilde{g}_{\tilde{g} \boldsymbol{\theta}}^{-1}\right) \widetilde{g} \mathbf{u}=\left(\widetilde{g} \widetilde{g}_{\boldsymbol{\theta}}\right)^{-1} \widetilde{g} \mathbf{u}=\widetilde{g}_{\boldsymbol{\theta}}^{-1} \widetilde{g}^{-1} \widetilde{g} \mathbf{u}=\widetilde{g}_{\boldsymbol{\theta}}^{-1} \mathbf{u}=M(\boldsymbol{\theta}, \mathbf{u})
$$

by Lemma 1 and the structure preserving properties of homomorphisms. Thus $M$ is $G^{\bullet}$ - invariant. To see that $M$ is maximal, let $M\left(\boldsymbol{\theta}_{1}, \mathbf{u}_{1}\right)=M\left(\boldsymbol{\theta}_{2}, \mathbf{u}_{2}\right)$. Then $\tilde{g}_{\boldsymbol{\theta}_{1}}^{-1} \mathbf{u}_{1}=\widetilde{g}_{\boldsymbol{\theta}}^{-1} \mathbf{u}_{2}$ or $\mathbf{u}_{1}=\widetilde{g} \mathbf{u}_{2}$, where $\tilde{g}=\widetilde{g}_{\boldsymbol{\theta}_{1}} \tilde{g}_{\boldsymbol{\theta}^{-1}}^{-1}$. Since $\boldsymbol{\theta}_{1}=\bar{g}_{\boldsymbol{\theta}}, \boldsymbol{\theta}_{0}=$ $\bar{g}_{\boldsymbol{\theta}_{1}}, \bar{g}_{\boldsymbol{\theta}}^{-1}, \boldsymbol{\theta}_{2}=\bar{g}_{\boldsymbol{\theta}},\left(\boldsymbol{\theta}_{1}, \mathbf{u}_{1}\right)=g^{\boldsymbol{\bullet}}\left(\boldsymbol{\theta}_{2}, \mathbf{u}_{2}\right)$ for some $g^{\boldsymbol{\bullet}} \in G \cdot$, and the proof is complete. 
Corollary 1.1 (Invariant embedding). An invariant function, $r(\boldsymbol{\theta}, \mathbf{u})$, can be transformed as follows:

$$
r(\boldsymbol{\theta}, \mathbf{u})=r\left(\bar{g}_{\hat{\boldsymbol{\theta}}}^{-1} \boldsymbol{\theta}, \tilde{g}_{\hat{\boldsymbol{\theta}}}^{-1} \mathbf{u}\right)=\ddot{r}(\mathbf{v}, \boldsymbol{\eta}),
$$

where $\mathbf{v}=\mathbf{v}(\boldsymbol{\theta}, \hat{\boldsymbol{\theta}})$ is a function (it is called a pivotal quantity) such that the distribution of $\mathbf{v}$ does not depend on $\boldsymbol{\theta} ; \boldsymbol{\eta}=\boldsymbol{\eta}(\mathbf{u}, \hat{\boldsymbol{\theta}})$ is an ancillary factor; $\hat{\boldsymbol{\theta}}$ is the maximum likelihood estimator of $\theta$ (or the sufficient statistic for $\theta$ ).

Corollary 1.2 (Best invariant decision rule). If $r(\boldsymbol{\theta}, \mathbf{u})$ is an invariant loss function, the best invariant decision rule is given by

$$
\varphi^{*}(\mathbf{x})=\mathbf{u}^{*}=\boldsymbol{\eta}^{-1}\left(\boldsymbol{\eta}^{*}, \widehat{\boldsymbol{\theta}}\right),
$$

where

$$
\boldsymbol{\eta}^{*}=\arg \inf _{\boldsymbol{\eta}} E_{\boldsymbol{\eta}}\{\ddot{r}(\mathbf{v}, \boldsymbol{\eta})\}
$$

Corollary 1.3 (Risk). A risk function (performance index)

$$
R(\boldsymbol{\theta}, \boldsymbol{\varphi}(\mathbf{x}))=E_{\boldsymbol{\theta}}\{r(\boldsymbol{\theta}, \boldsymbol{\varphi}(\mathbf{x}))\}=E_{\boldsymbol{\eta}}\left\{\ddot{r}\left(\mathbf{v}_{\circ}, \boldsymbol{\eta}_{\mathrm{o}}\right)\right\}
$$

is constant on orbits when an invariant decision rule $\boldsymbol{\varphi}(\mathbf{x})$ is used, where $\mathbf{v}_{\circ}=\mathbf{v}_{\circ}(\boldsymbol{\theta}, \mathbf{x})$ is a function whose distribution does not depend on $\theta$; $\eta_{0}=\eta_{0}(\mathbf{u}, \mathbf{x})$ is an ancillary factor. For instance, consider the problem of estimating the location-scale parameter of a distribution belonging to a family generated by a continuous cdf $F: \mathrm{P}=\left\{P_{\boldsymbol{\theta}}: F((x-\mu) / \sigma), x \in R, \theta \in \Theta\right\}, \Theta=\{(\mu, \sigma): \mu, \sigma$ $\in R, \sigma>0\}=\mathrm{U}$. The group $G$ of location and scale changes leaves the class of models invariant. Since $\bar{G}$ induced on $\Theta$ by $P_{\boldsymbol{\theta}} \rightarrow \theta$ is uniquely transitive, we may apply Theorem 1 and obtain invariant loss functions of the form

$r(\boldsymbol{\theta}, \boldsymbol{\varphi}(x))=r\left[\left(\varphi_{1}(x)-\mu\right) / \sigma, \varphi_{2}(x) / \sigma\right]$,

where

$\theta=(\mu, \sigma)$ and $\varphi(x)=\left(\varphi_{1}(x), \varphi_{2}(x)\right)$.

Let $\widehat{\boldsymbol{\theta}}=(\widehat{\mu}, \widehat{\sigma})$ and $\mathbf{u}=\left(u_{1}, u_{2}\right)$, then

$r(\boldsymbol{\theta}, \mathbf{u})=\ddot{r}(\mathbf{v}, \boldsymbol{\eta})=\ddot{r}\left(v_{1}+\eta_{1} v_{2}, \eta_{2} v_{2}\right)$,

where

$$
\begin{aligned}
& \mathbf{v}=\left(v_{1}, v_{2}\right), v_{1}=(\hat{\mu}-\mu) / \sigma, v_{2}=\hat{\sigma} / \sigma ; \\
& \boldsymbol{\eta}=\left(\eta_{1}, \eta_{2}\right), \eta_{1}=\left(u_{1}-\hat{\mu}\right) / \hat{\sigma}, \eta_{2}=u_{2} / \hat{\sigma} .
\end{aligned}
$$




\section{Application to Personnel Management Problem in Tourism}

Personnel management forms a significant proportion of overall costs in hotels, tourism companies and fast food restaurants. A reduction in this by even $1 \%$ represents considerable cost savings. Demand for services is not generally known with certainty before hand and management often relies on a combination of intuition, software systems and local knowledge (particularly of marketing campaigns, events and attractions). Staff scheduling is a key element of management planning in such circumstances. There have been a number of general survey papers in the area of personnel management; these include (Bechtold, Brusco and Showalter, 1991) and (Tien and Kamiyama, 1982). The latter survey concentrates on general labour scheduling models. A survey of crew scheduling is given in (Bodin, Golden, Asad and Ball, 1983). Surveys of the literature in airline crew scheduling appear in (Arabeyre, Fearnley, Steiger and Teather, 1969; Gamache and Soumis, 1998). A good survey of tools, models and methods for bus crew scheduling is (Wren, 1981). A survey of the nurse scheduling literature is provided in (Bradley and Martin, 1991; Sitompul and Radhawa, 1990). As can be seen from this review, a large amount of work has already been done in the area of personnel scheduling. Nevertheless there is still significant room for improvements in this area. We see improvements occurring not only in the area of tools, models and methods for personnel management, but also in the wider applicability of these tools, models and methods. In this paper, we consider the following personnel management problem in tourism. A certain company provides interpreter-guides for tourists. The number of permanent interpreter-guides employed by the company is such that $u$ of them are permanently working on a monthly basis at a daily guaranteed salary $c_{1}$ (in terms of money); when the demand for their services exceeds $u$, supplementary interpreter-guides or extras are taken on at a daily salary $c_{2}\left(>c_{1}\right)$. Sometimes the shortage of extras will necessitate canceling a tour, and when this happens, the loss is reckoned at $c_{3}\left(>c_{2}\right)$. How many permanent interpreter-guides should the company employ so that overall costs will be minimal? Following Kaufmann and Faure (Kaufman and Faure, 1968), we review the personnel management model and provide a broader interpretation to the structure of its solution. In development of the personnel management model, we will assume that the daily demand for tours $X$ is a continuous nonnegative random variable with the probability density function 
$f_{\theta}(\mathrm{x})$ and cumulative distribution function $F_{\theta}(x)$. The notation, we use for the personnel management model, is given below.

$X$

$f_{\theta}(y)$

$F_{\theta}(y)$

6

Y

$p(y)$

$c_{1}$

$c_{2}$

$c_{3}$

$u \quad$ Variable representing the number of the permanent interpreter-guides $u^{*} \quad$ Optimal quantity of the number of the permanent interpreter-guides $C(u)$

Random variable representing the daily demand for tours Probability density function of a demand $X$ Cumulative distribution function of a demand $X$ Parameter (in general, vector) Random variable representing the daily supply of extras Probability of a supply $y$, where $y=0,1, \ldots, \infty$ Daily guaranteed salary for the permanent interpreter-guide Daily salary for the supplementary (or extra) interpreter-guide Shortage cost per unit of $X$ Expected overall costs as a function of $u$

Thus, the function of overall costs is given by

$$
c(u, X, Y)=\left\{\begin{array}{ll}
c_{1} u, & 0 \leq X \leq u \\
c_{1} u+c_{2}(X-u), & u \leq X \leq u+Y . \\
c_{1} u+c_{2} Y+c_{3}(X-u-Y), & u+Y<X<\infty
\end{array} .\right.
$$

We write the expected overall costs as

$$
C u=E E_{\theta} c u X Y=\sum_{y=}^{\infty} p y \int^{\infty} c u x y f_{\theta} x d x=\sum_{y=}^{\infty} p y C u y
$$

where

$$
\begin{aligned}
& \text { Cuy }=\int_{0}^{\infty} c u x y f_{\theta} x d x \\
& =c u+c \int_{u}^{u+y} x-u f_{\theta} x d x+\int_{u+y}^{\infty} c y+c x-u-y f_{\theta} x d x
\end{aligned}
$$

The function $C(u)$ can be shown to be convex in $u$, thus having a unique minimum. Taking the first derivative of $C(u)$ with respect to $u$ and equating it to zero, we get 


$$
\sum_{y=0}^{\infty} p(y)\left(c_{1}-c_{2} \int_{u}^{u+y} f_{\theta}(x) d x-c_{3} \int_{u+y}^{\infty} f_{\theta}(x) d x\right)=0 .
$$

The value of $u$ that minimizes (17) is the one that satisfies

$$
c_{2} \bar{F}_{\theta}\left(u^{*}\right)+\left(c_{3}-c_{2}\right) \sum_{y=0}^{\infty} p(y) \bar{F}_{\theta}\left(u^{*}+y\right)=c_{3}-c_{1} \text {, }
$$

where

$$
\bar{F}_{\theta}(x)=1-F_{\theta}(x) \text {. }
$$

$$
\begin{aligned}
& \text { If } p(y=0)=1 \text {, then } \\
& F_{\theta}\left(u^{*}\right)=\frac{c_{3}-c_{1}}{c_{3}} .
\end{aligned}
$$

In this case, we should choose the $u^{*}$ such that the cumulative distribution function of $u^{*}$ equals the ratio of the difference of the underage and overage costs to the underage cost. A relatively high underage cost results in a higher number of the permanent interpreter-guides, whereas a relatively high overage cost leads to a lower number of the permanent interpreter-guides, as one would expect. If the daily demand for tours $X$ follows the exponential distribution with the probability density function

$$
f_{\sigma}(x)=\sigma^{-1} \exp (-x / \sigma), \sigma>0,
$$

and the cumulative distribution function

$$
F_{\sigma}(x)=1-\exp (-x / \sigma) \text {, }
$$

where $\sigma$ is the scale parameter $(\sigma>0)$, then

$$
C(u)=\sum_{y=0}^{\infty} p(y) C(u, y) \text {, }
$$

where

$$
C(u, y)=\sigma\left\lfloor c_{1} \frac{u}{\sigma}+c_{2} \exp \left(-\frac{u}{\sigma}\right)+\left(c_{3}-c_{2}\right) \exp \left(-\frac{u+y}{\sigma}\right)\right\rfloor
$$

and the value of $u$ that minimizes (23) is the one that satisfies 
$c_{2} \exp \left(-\frac{u^{*}}{\sigma}\right)+\left(c_{3}-c_{2}\right) \sum_{y=0}^{\infty} p(y) \exp \left(-\frac{u^{*}+y}{\sigma}\right)=c_{1}$.

If $p(y=0)=1$, then

$u^{*}=\sigma \ln \left(\frac{c_{3}}{c_{1}}\right)$

and

$C\left(u^{*}\right)=c_{1}\left\lfloor 1+\ln \left(\frac{c_{3}}{c_{1}}\right)\right\rfloor \sigma$.

Parametric uncertainty. Consider the case when the parameter $\sigma$ is unknown. Let $X_{1} \leq \ldots \leq X_{n}$ be the past observations (of the daily demand for tours) from the exponential distribution (21). Then

$$
S=\sum_{i=1}^{n} X_{i}
$$

is a sufficient statistic for $\sigma$; $S$ is distributed with

$$
g_{\sigma}(s)=\left[\Gamma(n) \sigma^{n}\right]^{-1} s^{n-1} \exp (-s / \sigma) \quad(s>0),
$$

To find the best invariant decision rule $u^{\mathrm{BI}}$, we use the invariant embedding technique (Nechval and Vasermanis, 2004; Nechval, N.A., Berzins, Purgailis, Nechval, K.N. and Zolova, 2008; Nechval, N.A., Nechval, K.N., Danovich and Liepins, 2011; Nechval, N.A., Nechval, K.N. and Purgailis 2011; Nechval, N.A., Nechval, K.N., Purgailis, Rozevskis, 2012; Nechval, N.A., Purgailis, 2012). to transform (24) to the form, which depends on the pivotal quantity $v=s / \sigma$, the ancillary factor $\eta=u / s$ and $y / s$,

$$
\begin{aligned}
& C(u, y)=\sigma\left[c_{1} \frac{u}{s} \frac{s}{\sigma}+c_{2} \exp \left(-\frac{u}{s} \frac{s}{\sigma}\right)+\left(c_{3}-c_{2}\right) \exp \left(-\frac{u+y}{s} \frac{s}{\sigma}\right)\right\rfloor \\
& =\sigma\left[c_{1} \eta v+c_{2} \exp (-\eta v)+\left(c_{3}-c_{2}\right) \exp \left(-\eta+\frac{y}{s}\right) v\right\rfloor=C(\eta, y, v \mid s) .
\end{aligned}
$$

We find the expected overall costs for the statistical decision $u=\eta S$ as

$$
C(\eta \mid s)=\sum_{y=0}^{\infty} p(y) C(\eta, y \mid s) \text {, }
$$


where

$$
\begin{aligned}
& C(\eta, y \mid s)=\int_{0}^{\infty} C(\eta, y, v \mid s) g(v) d v, \\
& =\sigma\left\lfloor c_{1} \eta n+c_{2} \frac{1}{(1+\eta)^{n}}+\left(c_{3}-c_{2}\right)\left(1+\eta+\frac{y}{s}\right)^{-n}\right\rfloor, \\
& g(v)=[\Gamma(n)]^{-1} v^{n-1} \exp (-v) \quad(v>0) .
\end{aligned}
$$

The value of $\eta$ that minimizes (31) is the one that satisfies

$$
c_{2} \frac{1}{\left(1+\eta^{*}\right)^{n+1}}+\left(c_{3}-c_{2}\right) \sum_{y=0}^{\infty} p(y)\left(1+\eta^{*}+\frac{y}{s}\right)^{-(n+1)}=c_{1} \text {. }
$$

Thus,

$$
u^{\mathrm{BI}}=\eta^{*} S \text {. }
$$

If $p(y=0)=1$, then

$$
\eta^{*}=\left(\frac{c_{3}}{c_{1}}\right)^{1 /(n+1)}-1
$$

and

$$
C\left(\eta^{*} \mid s\right)=\sigma\left[c_{1} \eta^{*} n+c_{3} \frac{1}{\left(1+\eta^{*}\right)^{n}}\right]=c_{1}\left\lfloor\left(\frac{c_{3}}{c_{1}}\right)^{1 /(n+1)}(n+1)-n\right\rfloor \sigma .
$$

Comparison of decision rules. For comparison, consider the maximum likelihood decision rule that can be obtained from (26) as

$$
u^{\mathrm{ML}}=\hat{\sigma} \ln \left(\frac{c_{3}}{c_{1}}\right)=\eta^{\mathrm{ML}} S,
$$

where $\hat{\sigma}=S / n$ is the maximum likelihood estimator of $\sigma$,

$$
\eta^{\mathrm{ML}}=\ln \left(\frac{c_{3}}{c_{1}}\right)^{1 / n}
$$

Since $u^{\mathrm{BI}}$ and $u^{\mathrm{ML}}$ belong to the same class

$$
\mathrm{C}=\{u: u=\eta S\} \text {, }
$$


it follows from the above that $u^{\mathrm{ML}}$ is inadmissible in relation to $u^{\mathrm{BI}}$. If, say, $c_{1}=50, c_{3}=3500$ (in terms of money), and $n=1$, we have that

rel.eff. ${ }_{C(\eta \mid s)}\left\{u^{\mathrm{ML}}, u^{\mathrm{BI}}, \sigma\right\}=C\left(\eta^{*} \mid s\right) / C\left(\eta^{\mathrm{ML}} \mid s\right)$

$$
=\frac{c_{1} \eta^{*} n+c_{3} \frac{1}{\left(1+\eta^{*}\right)^{n}}}{c_{1} \eta^{\mathrm{ML}} n+c_{3} \frac{1}{\left(1+\eta^{\mathrm{ML}}\right)^{n}}}=0.90 \text {. }
$$

Thus, in this case, the use of $u^{\mathrm{BI}}$ leads to a reduction in the expected overall costs of about $10 \%$ as compared with $u^{\mathrm{ML}}$. The absolute expected overall costs will be proportional to $\sigma$ and may be considerable.

Predictive inference. It will be noted that the predictive probability density function of the daily demand for tours, $X$, which is compatible with (15), is given by

$$
f(x \mid s)=\frac{n+1}{s}\left(1+\frac{x}{s}\right)^{-(n+2)} \quad(x>0) .
$$

Using (42), the predictive overall costs are determined as

$$
C^{(p)}(u \mid s)=\sum_{y=0}^{\infty} p(y) C^{(p)}(u, y \mid s),
$$

where

$$
\begin{aligned}
& C^{(p)}(u, y \mid s)=c_{1} u+c_{2} \int_{u}^{u+y}(x-u) f(x \mid s) d x+\int_{u+y}^{\infty}\left[c_{2} y+c_{3}(x-u-y)\right] f(x \mid s) d x \\
= & \frac{s}{n}\left[c_{1} \frac{u}{s} n+c_{2}\left(1+\frac{u}{s}\right)^{-n}+\left(c_{3}-c_{2}\right)\left(1+\frac{u}{s}+\frac{y}{s}\right)^{-n}\right],
\end{aligned}
$$

which can be reduced to

$$
C^{(p)}(\eta, y)=\frac{s}{n}\left\lfloor c_{1} \eta n+c_{2} \frac{1}{(1+\eta)^{n}}+\left(c_{3}-c_{2}\right)\left(1+\eta+\frac{y}{s}\right)^{-n}\right\rfloor
$$

Thus, It follows from (32) and (45) that $u^{\mathrm{BI}}$ can be found immediately from (43) as

$$
u^{\mathrm{BI}}=\arg \min _{u} C^{(p)}(u \mid s) .
$$




\section{Conclusions and Directions for Future Research}

In this paper, we propose a new technique to improve or optimize statistical decisions under parametric uncertainty. The method used is that of the invariant embedding of sample statistics in a performance index in order to form pivotal quantities, which make it possible to eliminate unknown parameters (i.e., parametric uncertainty) from the problem. It is especially efficient when we deal with asymmetric performance indexes and small data samples. More work is needed, however, to obtain improved or optimal decision rules for the problems of unconstrained and constrained optimization under parameter uncertainty when: (i) the observations are from general continuous exponential families of distributions, (ii) the observations are from discrete exponential families of distributions, (iii) some of the observations are from continuous exponential families of distributions and some from discrete exponential families of distributions, (iv) the observations are from multiparametric or multidimensional distributions, (v) the observations are from truncated distributions, (vi) the observations are censored, (vii) the censored observations are from truncated distributions. 


\section{Bibliography}

- Conrad, S.A. (1976). Data and the estimation of demand. Oper. Res. Quart. 27: pp. 123-127.

- Liyanage, L.H., Shanthikumar, J.G. (2005). A practical inventory policy using operational statistics. Operations Research Letters 33: pp. 341-348.

- Scarf, H. (1959). Bayes solutions of statistical inventory problem. Ann. Math. Statist. 30: pp. 490 -508.

- Chu, L.Y., Shanthikumar, J.G., Shen, Z.J.M. (2008). Solving operational statistics via a Bayesian analysis. Operations Research Letters 36: pp. 110 -116.

- Bookbinder, J.H., Lordahl, A.E. (1989). Estimation of inventory reorder level using the bootstrap statistical procedure. IIE Trans. 21: pp. 302-312.

- Scarf, H. (1958). A min-max solution of an inventory problem. Studies in the Mathematical Theory of Inventory and Production (Chapter 12). Stanford: Stanford University Press.

- Gallego, G., Moon, I. (1993). The distribution free newsvendor problem: review and extensions. J. Oper. Res. Soc. 44: pp. 825-834.

- Nechval, N. A., Vasermanis, E. K. (2004). Improved Decisions in Statistics. Riga: Izglitibas Soli.

- Nechval, N.A., Berzins, G., Purgailis, M., Nechval, K.N. (2008). Improved estimation of state of stochastic systems via invariant embedding technique. WSEAS Transactions on Mathematics 7: pp. 141-159.

- Nechval, N.A., Berzins, G., Purgailis, M., Nechval, K.N., Zolova, N. (2009). Improved adaptive control of stochastic systems. Advances in Systems Science and Applications 9: pp. 11-20.

- Nechval, N.A., Nechval, K.N., Danovich, V., Liepins, T. (2011). Optimization of new-sample and within-sample prediction intervals for order statistics. In: Proceedings of the 2011 World Congress in Computer Science, Computer Engineering, and Applied Computing. WORLDCOMP'11, 18-21 July, 2011, Las Vegas, Nevada, USA, pp. 91-97.

- Nechval, N.A., Nechval, K.N., Purgailis, M. (2011). Statistical inferences for future outcomes with applications to maintenance and reliability. In: Lecture Notes in Engineering and Computer Science: Proceedings of the World Congress on Engineering 2011, WCE 2011, 6-8 July, 2011, London, U.K., pp. 865-871.

- 13. Nechval, N.A., Nechval, K.N., Purgailis, M., Rozevskis, U. (2012). Optimal prediction intervals for order statistics coming from locationscale families. Engineering Letters 20: pp. 353-362.

- 14. Nechval, N.A., Purgailis, M. (2012). Stochastic control and improvement of statistical decisions in revenue optimization systems. In: Stochastic Modeling and Control, Ivan Ganchev Ivanov (Ed.). Croatia: Sciyo, pp. 185-210. 
- Bechtold, S., Brusco, M., Showalter, M. (1991). A comparative evaluation of labor tour scheduling methods. Decision Sciences 22: pp. 683 - 699.

- Tien, J., Kamiyama, A. (1982). On manpower scheduling algorithms. SIAM Review 24: pp. 275-287.

- $\quad$ Bodin, L., Golden, B., Assad, A., Ball, M. (1983). Routing and scheduling of vehicles and crews - the state of the art. Computers and Operations Research 10: pp. $63-211$.

- Arabeyre, J., Fearnley, J., Steiger, F., Teather, W. (1969). The airline crew scheduling problem: a survey. Transportation Science 3: pp. 140-163.

- Gamache, M., Soumis, F. (1998). A method for optimally solving the rostering problem. In: OR in Airline Industry, G. Yu (Ed.). Boston: Kluwer Academic Publishers, pp. 124-157.

- Wren, A. (1981). A general review of the use of computers in scheduling buses and their crews. In: Computer Scheduling of Public Transport, Urban Passenger Vehicle and Crew Scheduling, A. Wren (Ed.). NorthHolland, Amsterdam, pp. 3-16.

- Bradley, D., Martin, J. (1991). Continuous personnel scheduling algorithms: a literature review. Journal of the Society for Health Systems 2: pp. 2-8.

- Sitompul, D., Radhawa, S. (1990). Nurse scheduling: a state-of-the-art review. Journal of the Society for Health Systems 2: pp. 62-72.

- Kaufmann, A., Faure, R. (1968). Introduction to Operations Research. New York: Academic Press. 
Prof. dr Nicholas A. Nechval,

Letonski univerzitet, Letonija

Doc. dr Gundars Berzins,

Letonski univerzitet, Letonija

Dr Vadim Danovich, vanredni profesor

Letonski univerzitet, Letonija

Dr Konstantin N. Nechval, vanredni profesor

Saobraćajni i telekomunikacioni Institut, Letonija

\title{
OPTIMIZACIJA U USLOVIMA NEIZVESNOSTI SA PRIMENAMA U UPRAVLJANJU LJUDSKIM RESURSIMA U TURIZMU
}

\begin{abstract}
S a ž e $t$ a k
Brojni problemi koji nastaju prilikom planiranja, proizvodnje, zakazivanja, lokacija, transporta, finansija i potrebnom inžinjerskom dizajnu, zahtevaju da se odluke donose s dozom neizvesnosti.

Za poboljšanje i optimizaciju odluka, predložena je jedna nova tehnika. Ona predstavlja jednostavnu i atraktivnu statističku metodu koja se bazira na osnovu konstruktivnog korišćenja matematičke statistike. Suprotno Bajesovskom pristupu, ova tehnika ne dozvoljava slobodu izbora ali dopušta eliminaciju nepoznatih parametara u odnosu na problem.

S ciljem predstavljanja primene predloženih tehnika razrađeni su problemi koji se pojavljuju prilikom upravljanja u turizmu, na primeru kompanije koja pruža usluge prevodilaca/ vodiča turistima.
\end{abstract}

Ključne reči: optimizacija, problem upravljanja ljudskim resursima 